\title{
The Optimum Link Design Using a Linear PIN-PD for WiMAX RoF Communication
}

\author{
Koyu Chinen \\ Okinawa National College of Technologies \\ Japan
}

\section{Introduction}

Worldwide Interoperability for Microwave Access (WiMAX) is a new standard for highspeed wireless communication that covers wider area than that of Wireless Local Area Network (WLAN). In the WiMAX, the original data are first mapped on the symbols of Quadrature Phase Shift Keying (QPSK), 16 Quadrature Amplitude Modulation (QAM), or 64 QAM, depending on the data speed. The complex numbers of the symbols are allocated to subcarriers and the subcarriers are converted to time-domain I and Q data by Inverse Fast Fourier Transform (IFFT) algorithm. The parallel data of I and Q are converted to serial data by using a parallel to serial converter. The digital serial data are converted to analog data by using digital to analog converter. The analog I and $Q$ data are orthogonally modulated by a carrier frequency and multiplexed to generate a time domain waveform. Therefore, in the Orthogonal Frequency Division Multiplexing (OFDM), the Peak-to-Average Power Ratio (PAPR) of the waveform becomes higher when the number of sub-carriers increases. When the waveform is converted by Electrical-Optical converter (E/O) to optical signal and transmitted over a fiber and is converted by Optical-Electrical converter $(\mathrm{O} / \mathrm{E})$ to electrical signal, the larger PAPR causes larger distortion in those optical components. Therefore it is strictly important to design the WiMAX communication link by using highly linear optical signal converters. Since the linearity in the actual optical components is insufficient to cover all modulation conditions in the WiMAX communications, the optimum design of the E/O, the $\mathrm{O} / \mathrm{E}$, the modulation, and the demodulation is necessity, based on the specific condition of the communication systems. But it is obvious to use the linear PIN photodiode (PIN-PD) for all of the WiMAX Radio-over-Fiber (RoF) links. Because, the structure and the performance are stable and simple, in comparison with that of other active optical components, such as Avalanche Photo diode (APD) and Distribute feedback Laser diode (DFB-LD).

\section{An RCE calculation model for RoF of WiMAX}

Relative Constellation Error (RCE) is an important standard for evaluation of the transmission quality in the WiMAX. Since the modulation of the WiMAX consists of QPSK, QAM, and OFDM, the RCE is sensitive to the change in the phase and the amplitude of the signals. The phase and the amplitude of the signals are influenced with optical components. 
Therefore in the Radio over Fiber (RoF) link, the RCE is determined with many component factors, such as the modulation power, the type of optical transmitters, optical fiber length, optical receiver, and the type of antennas.

An RCE calculation model was theoretically and experimentally derived, for the RoF system of the WiMAX, when the system was configured with linear characteristic components and the Polarization Mode Dispersion (PMD) was suppressed by an optimum modulation condition. In hybrid optical links, the influence of the WiMAX signal on the digital baseband was also investigated [1]. It is also important to characterize the WiMAX signal behavior in the digital optical links.

\subsection{RCE degradation due to PMD and PML}

The Polarization Mode Dispersion (PMD) and the Polarization Mode coupling Loss (PML) were suspected in the RoF link. A measurement setup shown in Fig.2.1 was used to investigate its influence on the RCE. The baseband signal generated at a vector signal generator (VSG) complies with the IEEE 802.16-2004 downlink standard. The sub-frame structure of the WiMAX signal generated included three types of the burst data of QPSK, 16QAM, and 64QAM. Three different types of DFB lasers were evaluated as the optical transmitter [2].

The receiver was an 80 micron diameter InGaAs PIN-PD packaged in a coaxial pigtail module. The responsivity is $0.85 \mathrm{~A} / \mathrm{W}$ in the typical, the cutoff frequency is $2 \mathrm{GHz}$, the capacitance is $1.3 \mathrm{pF}$ or less.

Since this PIN-PD is designed for analog transmissions, the secondary order Intermodulation Distortion (IMD2) is less than $-75 \mathrm{dBc}$, the third order Intermodulation Distortion (IMD3) is less than $-90 \mathrm{dBc}$, with two tones of $244 \mathrm{MHz}$ and $250 \mathrm{MHz}$, at an Optical Modulation Depth (OMD) of $70 \%$. The load resistance is $50 \Omega$. This low gain circuit is sensitive to the degradation of the carrier to noise ratio (CNR) of the receiving signal. When the fiber length, the signal frequency, and the PMD and PML change, the digradation in the CNR affects the RCE in the WiMAX transmission.

The RCE was measured at a Vector Signal Analyzer (VSA). To investigate the influence of the carrier frequency and the fiber length, the frequency changed from 1 to $2.5 \mathrm{GHz}$, and the standard single-mode-fiber (SMF) length changed from 0 to $10 \mathrm{~km}$. The measured RCE was influenced strongly by the modulation carrier frequency and the fiber length, as shown in Fig.2.2. At higher frequency the RCE measurement results were unstable. This is due to the PMD caused in the SMF. In case of the lower RCE, the constellation map showed small size dots, as shown in Fig.2.3 (a). But, the RCE for all sub-frames measured after the 10km SMF, showed large deviations in the magnitude and the phase, as shown in Fig.2.3 (b). When increasing the reflected light intensity into the fused-type optical coupler, the RCE showed increase of the magnitude, as shown in Fig.2.3(c). This was due to the PML caused in the fused-type optical coupler. The returned light did not affect the transmitter noise, since there was a $60 \mathrm{~dB}$ optical isolator in front of the DFB laser. In addition to the fact, it was also confirmed that the returned light did not cause any instability in the RCE, when the isolation at the DFB laser decreased to $30 \mathrm{~dB}$. These results were the same for the $1550 \mathrm{~nm}$ Multi Quantum Well (MQW) laser, 1310nm MQW laser, and 1310nm Electro-AbsorptionModulator integrated DFB laser. The optimization of the carrier frequency and the fiber length has to be first carried out to achieve the lower RCE. 


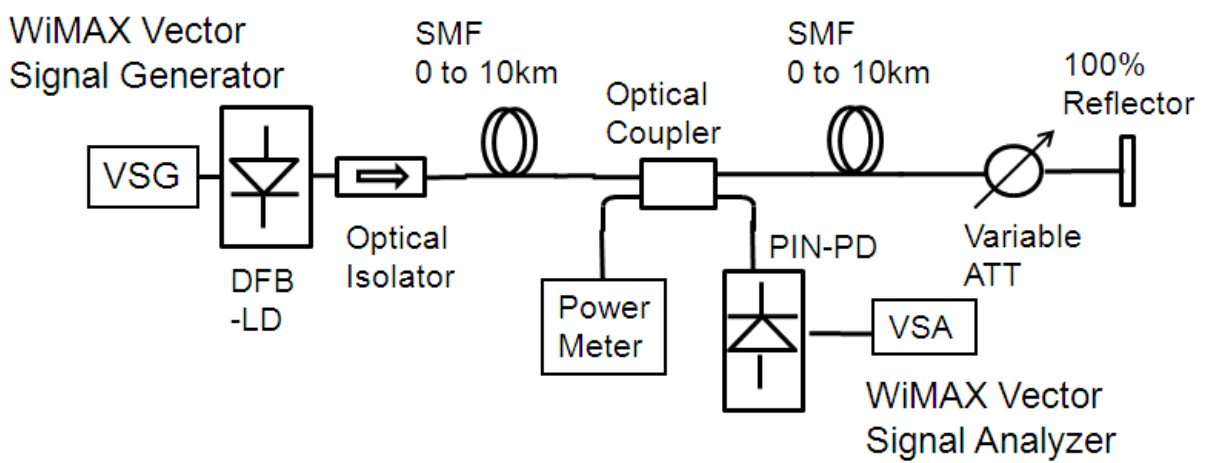

Fig. 2.1. The RCE measurement setup configured with DFB laser, single mode fiber, optical coupler, and optical reflector.

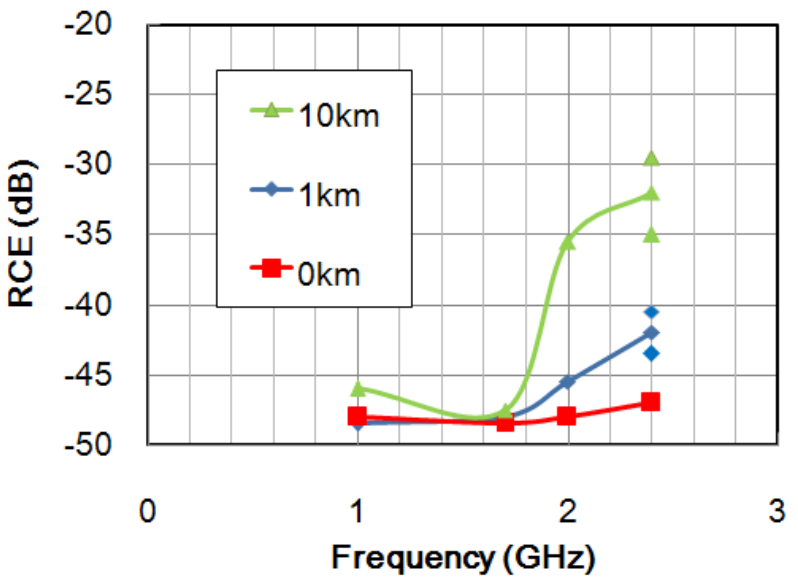

Fig. 2.2. The RCE was measured with different fiber lengths and modulation frequencies.

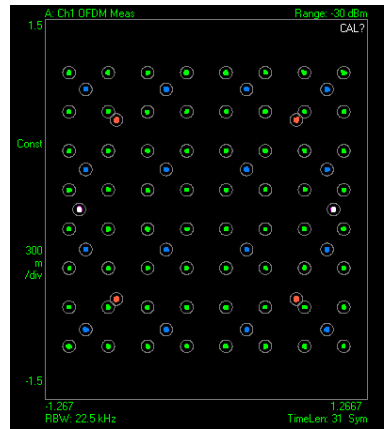

(a)

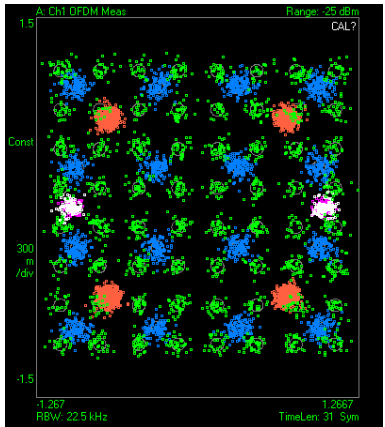

(b)

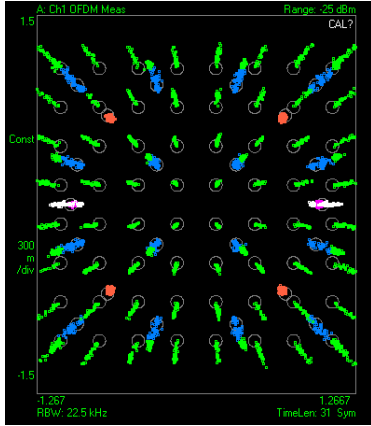

(c)

Fig. 2.3. (a): Constellation on normal condition, (b): with degradation by the PMD, and (c): with degradation by the PML. 


\subsection{An RoF and wireless link system configuration}

It was found that the RCE of the WiMAX was determined with the burst signal waveform, and that the PAPR at a Complementary Cumulative Distribution Function (CCDF) was not changed by the carrier modulation bandwidth for the burst signal waveform, and was close to the Gaussian curve. Therefore the RCE was not varied with the carrier modulation bandwidth between 5 to $20 \mathrm{MHz}$. When the RoF link was constructed with electrically and optically linear characteristic components, the RCE was determined with theCNR of the received burst signal power. Figure 2.4. shows an RoF and wireless system used for the RCE measurements. The system was configured with a transmitter of the $1550 \mathrm{~nm}$ DFB laser, a standard 10km SMF, a PIN-PD receiver, and parabolic grid antennas.

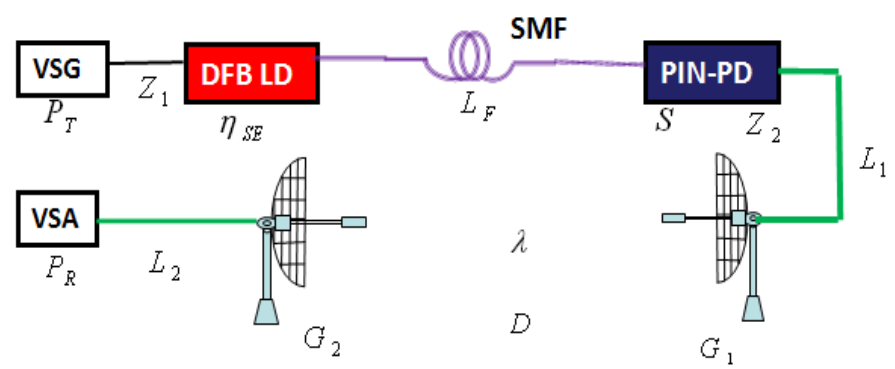

Fig. 2.4. The RoF and wireless system configured with DFB laser, optical single mode fiber, and $1.7 \mathrm{GHz}$ parabolic grid antennas.

\subsection{Received power in RoF}

By using the power level at each component of the signal generator (VSG), the DFB laser, the single mode fiber (SMF), the PIN-PD, the coaxial cables, the transmitter (Tx), the transmitter (Tx) parabolic antenna, space, and the receiver $(\mathrm{Rx})$ parabolic antenna, the received power at the signal analyzer (VSA) can be expressed as

$$
\begin{aligned}
P_{R}= & P_{T}-2 L_{F}+20 \log \left(\sqrt{\frac{Z_{2}}{Z_{1}}} \cdot \eta_{S E} \cdot S\right)-L_{1}-L_{2} \\
& +10 \log \left(\left(\frac{\lambda}{4 \pi D}\right)^{2}+G_{1}+G_{2}\right)
\end{aligned}
$$

where, $P_{R}[\mathrm{dBm}]$ is the received power at the VSA, $P_{T}[\mathrm{dBm}]$ is the DFB laser modulation power generated at the VSG, $L_{F}[\mathrm{~dB}]$ is the optical fiber loss, $Z_{1}[\Omega]$ is the DFB laser input impedance, $\eta_{S E}[\mathrm{~mW} / \mathrm{mA}]$ is the DFB laser slope efficiency, $S[\mathrm{~A} / \mathrm{W}]$ is the PIN-PD responsivity, $Z_{2}[\Omega]$ is the PIN-PD output impedance, $L_{1}[\mathrm{~dB}]$ and $L_{2}[\mathrm{~dB}$ ]are the cable loss, $D[\mathrm{~m}]$ is the antennas distance, $\lambda[\mathrm{m}]$ is the carrier wavelength, $G_{1}[\mathrm{dBi}]$ is the Tx antenna gain, and $G_{2}[\mathrm{dBi}]$ is the $\mathrm{Rx}$ antenna gain. In the calculation the following parameters are used; $L_{F}=2 \mathrm{~dB}, Z_{1}=25 \Omega, \eta_{S E}=0.17 \mathrm{~mW} / \mathrm{mA}, S=0.85 \mathrm{~A} / \mathrm{W}, Z_{2}=50 \Omega, L_{1}$ and $L_{2}=5 \mathrm{~dB}$ in total, $D=16 \mathrm{~m}, \lambda=0.17647 \mathrm{~m}, G_{1}=20 \mathrm{dBi}$, and $G_{2}=19 \mathrm{dBi}$.

The received power was measured with different system configurations. The first configuration used coaxial cables only between the VSG and VSA. The second one used the 
coaxial cable and the 10km optical fiber between the VSG and VSA. The third one used the coaxial cable, the $10 \mathrm{~km}$ optical fiber, and the parabolic grid antennas between the VSG and the VSA. Figure2.5 shows the experimental data and the theoretical data that are calculated with the equation (2.1). The experimental data of the received power coincided within $2 \mathrm{~dB}$ with the theoretical data.

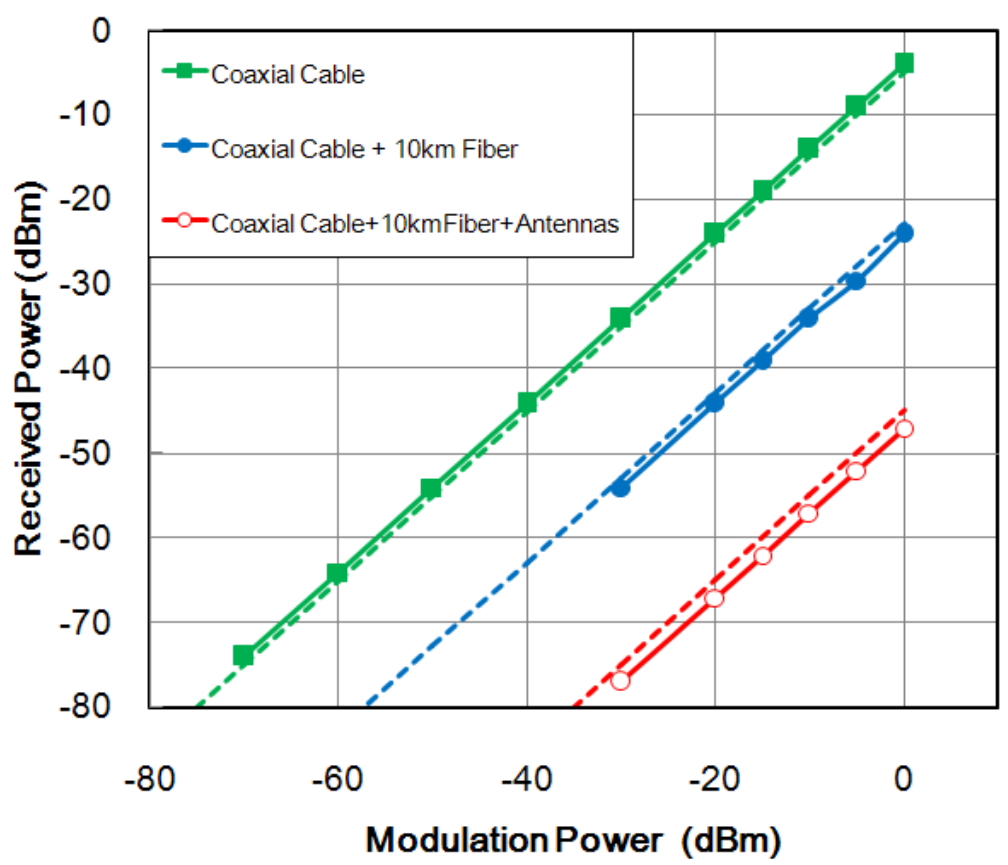

Fig. 2.5. The received powers were measured with modulation powers of driving the DFB laser for three different types of system configurations. The solid lines showed the experimental data and the dashed lines showed theoretical data calculated with the equation

\subsection{RCE in RoF of WiMAX}

It was considered that the RCE was determined with the received power and the noise power ratio when the RoF system was configured with linear characteristic components and the optimized modulation condition that were not influenced by the PMD and PML. However it is not realistic to completely eliminate the influence by the PMD and PML in the actual link system. A compensation factor to the received power has to be taken into account. Hence, the RCE is expressed using a compensation factor and a noise power as

$$
R C E=P_{N}-A \cdot P_{R}
$$

where, RCE $[\mathrm{dB}]$ is the Relative Constellation Error, $P_{R}[\mathrm{dBm}]$ is the received power, $\mathrm{A}$ is the compensation factor to the received power, and $P_{N}$ is the system noise power. In the calculation the following parameters are used; $\mathrm{A}=0.857$ and $P_{N}=-84.3[\mathrm{dBm}]$. 
The RCE was also measured with those three different system configurations. Figure 2.6 shows the experimental data and the theoretical data that are calculated with the equation (2.2). In the full components configuration system, the RCE experimental data coincide within $2 \mathrm{~dB}$ with the theoretical data. In the coaxial cable components configuration system, there was a little discrepancy between the experimental and the theoretical data in the lower RCE. This was due to that the noise power $P_{N}$ used in the calculation was derived for the full components configuration system. It is obvious that the noise power $P_{N}$ has to be used for unique value for each system configuration. But, by using the noise power $P_{N}$ of full components configuration system, the RCE for the different type of the configuration system can be estimated. This means that the equation (2.1) and (2.2) are valid for any components configuration of the RoF system for the WiMAX, and are useful for the RoF system design and analysis.

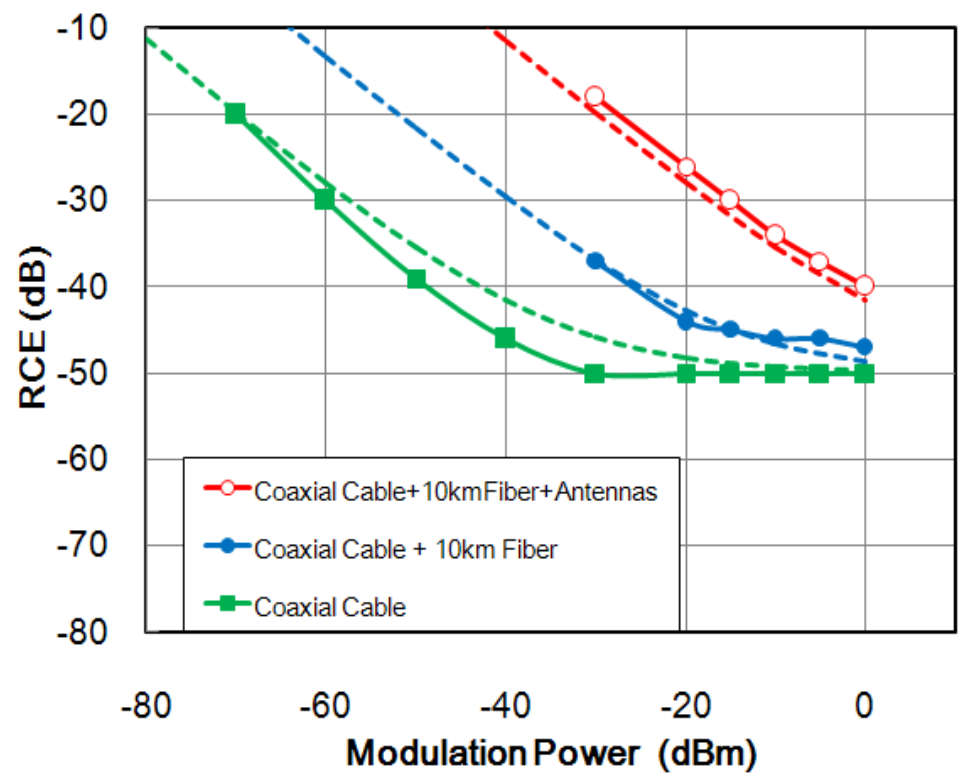

Fig. 2.6. The RCE were measured with modulation powers of DFB laser for the different type of system configurations. The solid lines show the experimental data and the dashed lines show theoretical data calculated with the equation (2.2).

It is possible to minimize the influence of the PMD and the PML by optimizing the carrier frequency, the fiber length, the type of the fiber, and the type of the coupler. The burst signal received power of the RoF of WiMAX was determined by the transmitter modulation, when the RoF link was configured with optically and electrically linear characteristic components. Since the RCE in the RoF of the WiMAX was related to the burst signal receiver power, the RCE was expressed in the linear relation with the burst signal received power. The experimental data and theoretical data mostly coincided within $2 \mathrm{~dB}$ for the received power and the RCE. 


\section{E/O and O/E in WiMAX RoF}

The WiMAX is a new standard for high-speed wireless communication that covers wider area than that of WLAN. For the field service, many access points are required, and it is important to design them with small size, low power consumption, and high reliability. Therefore, the complicated RF modem and signal processing functions are transferred from the access points to a central control office [3]. To extend the distance between the access points and the central office, the use of RoF is suitable for the WiMAX. There have been several studies of the lower cost and the high performance solutions for the RoF of WLAN [4]. The use of Vertical Cavity Surface Emitting Laser (VCSEL) or Fabry-Perot Laser Diode (FP-LD) was suggested for a low cost solution, and Mach-Zender Modulator (MZM) and Electro-Absorption Modulator (EAM) were used to achieve a high performance. However, there have been few studies for the RoF of WiMAX. A cost effective design was investigated for the E/O and the O/E that satisfy both the low cost and the high performance for the WiMAX RoF.

\subsection{WiMAX RoF access points}

In the WiMAX field service, a lot of access points are required, as shown in Fig.3.1. Therefore, it is important to design the access points with low power consumption, small mechanical size, high reliability, long distance installation, and low cost. A solution to those requirements is that the signal processing function such as the frequency up-down converter, modulator and demodulator, and A/D converter shall be transferred to the central office, and the access point is modified to the remote antenna unit (RAU) that has a transceiver antenna, and E/O and O/E converters [5], [6]. The RoF link enables installation of the access units in a long distance from the central office.

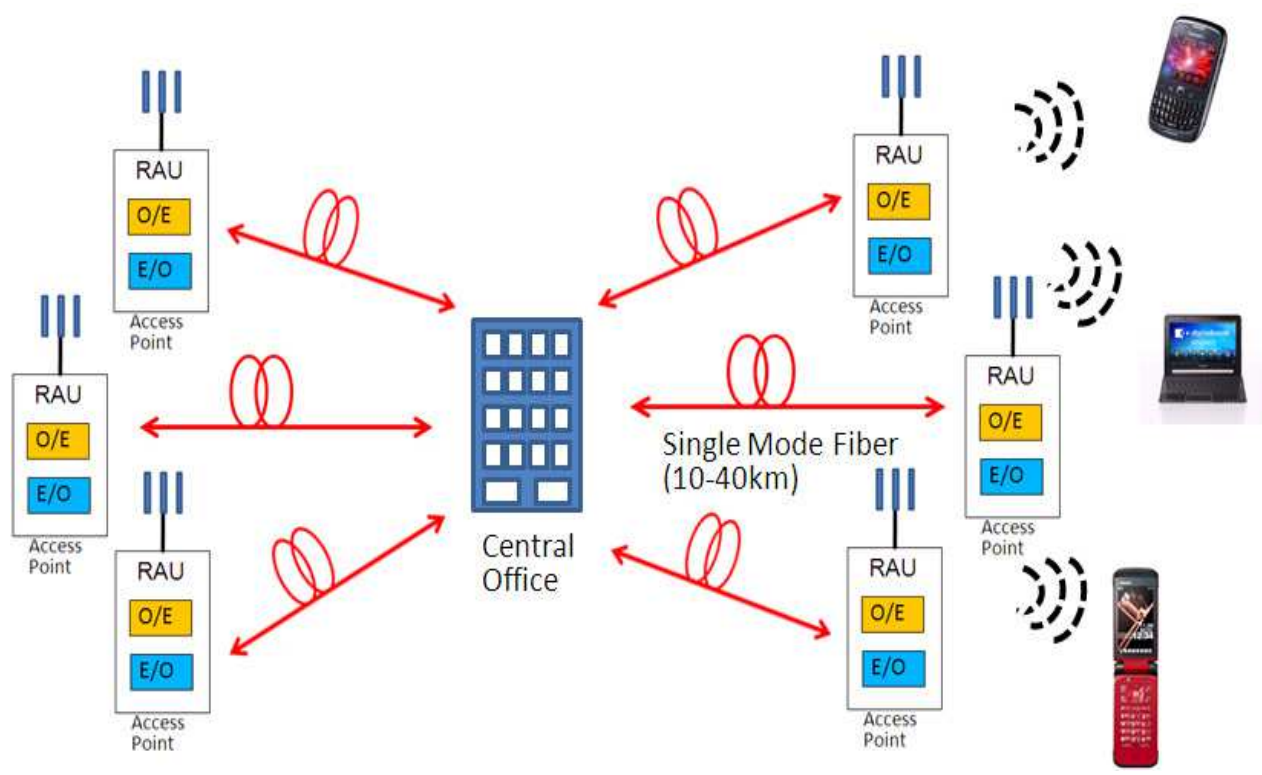

Fig. 3.1. The WiMAX RoF links connect between the central office and the access points. 


\subsection{Input Impedance adjustments in E/O converters}

Two different types of 1310nm InGaAsP lasers of DFB and FP type lasers were used for the E/O converter. The package of the laser was Transmitter Optical Sub-Assembly (TOSA) that was a low cost design with a receptacle optical interface. We investigated if the electrical and optical conversion efficiency was increased with adjusting the input impedance of the $\mathrm{E} / \mathrm{O}$ converter. The input impedance of the lasers at the $2.4 \mathrm{GHz}$ was adjusted on a network analyzer by changing the R, C, and L elements at the Radio-Frequency (RF) line of the BiasTee. In case of adjusting the input impedance to $50 \Omega$, the input impedance was moved from the initial value of $15-j 55 \Omega$ to the matching point of $49.5-\mathrm{j} 33 \Omega$ by adding $33 \Omega$ resistor, $1 \mathrm{nH}$ inductor, and $4.7 \mathrm{pF}$ capacitor to the RF line, as shown in Fig.3.2. In case of adjusting the input impedance to a low value, the impedance was moved from the initial value of 15j50 2 to the low value point of $7-\mathrm{j} 2.07 \Omega$ by adding $22 \mathrm{nH}$ inductor to the RF line, as shown in Fig.3.3. In case of FP-LD, in addition to the inductor, a capacitor was used. After the input impedance adjustment, the E/O conversion efficiency was measured by a light-wave optical component analyzer (N4373A+N5230A, Agilent). The low-impedance input laser modulation showed about $5 \mathrm{~dB}$ higher $\mathrm{E} / \mathrm{O}$ conversion efficiency than that of $50 \Omega$ input impedance laser, as shown in Table 3.1. Although the length of the RF coaxial cable was about $50 \mathrm{~cm}$, the electrical reflectance did not affect the E/O conversion efficiency.

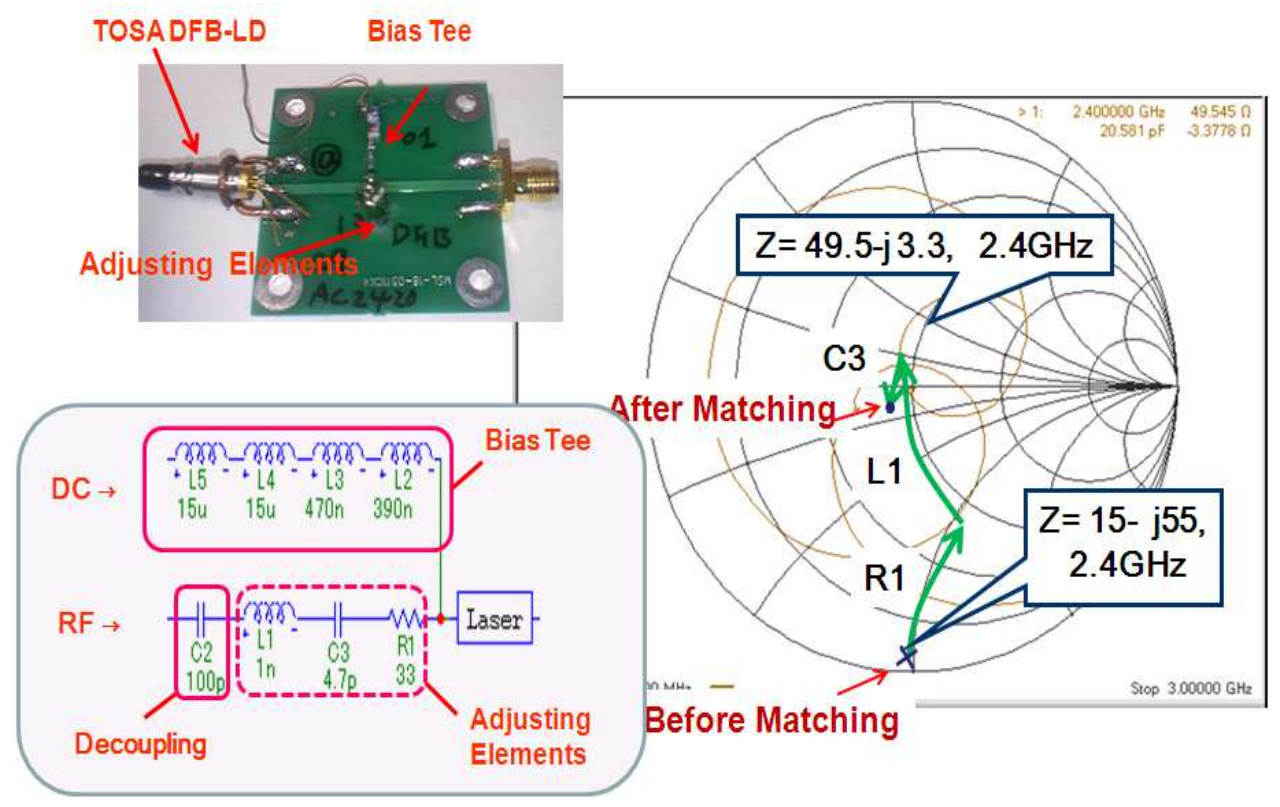

Fig. 3.2. TOSA type E/O with Bias-Tee, Bias-Tee circuit for $50 \Omega$ input- impedance adjusting, Input-impedance adjusting with R,C, and L elements, on a network analyzer. 


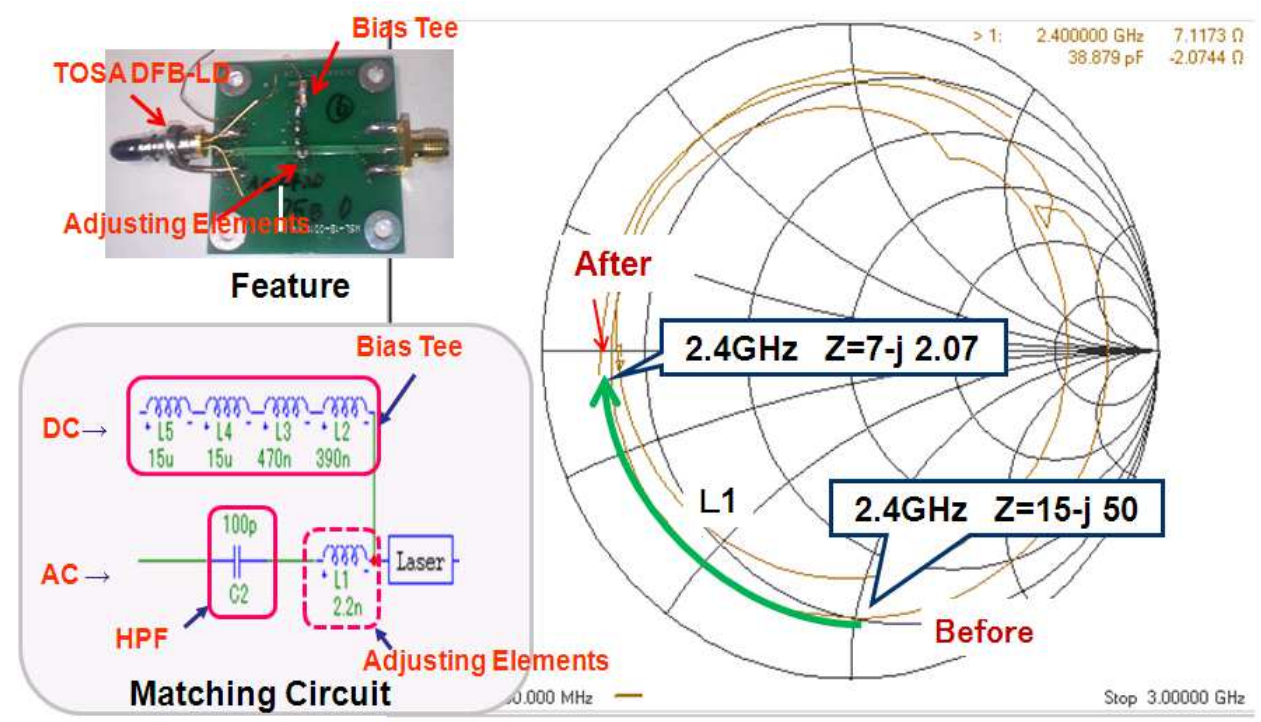

Fig. 3.3. TOSA type E/O with Bias-Tee, Bias-Tee circuit for input- low impedance adjusting, Input-impedance adjusting with L element, on a network analyzer.

\begin{tabular}{|l|c|c|c|}
\hline \multirow{2}{*}{ Symbol } & \multicolumn{2}{|c|}{ Input Impedance Adjusting } & E/O Conversion \\
\cline { 2 - 4 } & Before $(\Omega)$ & After $(\Omega)$ & $(2.4 \mathrm{GHz})(\mathrm{dB})$ \\
\hline DFB-Low & $15-\mathrm{j} 50$ & $7-\mathrm{j} 2.07$ & -8.3 \\
\hline DFB-50 $\Omega$ & $15-\mathrm{j} 55$ & $49.5-\mathrm{j} 3.3$ & -12 \\
\hline FP-Low & $12-\mathrm{j} 19$ & $11-\mathrm{j} 3.95$ & -13 \\
\hline FP-50 $\Omega$ & $12-\mathrm{j} 19$ & $50-\mathrm{j} 0.093$ & -18 \\
\hline
\end{tabular}

Table 3.1. E/O input-impedance adjusting and E/O conversion

The E/O conversion of the laser is able to be derived by the following equation;

$$
\eta_{E O}=20 \cdot \log \left(\eta_{S E} \cdot \sqrt{\frac{50}{Z_{\text {in }}}}\right)[d B]
$$

where, $\eta_{E O}$ is the electrical and optical conversion efficiency $[\mathrm{dB}], \quad \eta_{S E}$ is the laser slope efficiency $[\mathrm{W} / \mathrm{A}]$, and $Z_{\text {in }}$ is the laser input impedance $[\Omega]$.

According to the equation (3.1), the electrical optical conversion efficiency of the low input impedance laser is higher than that of the $50 \Omega$ input impedance laser by 7 to $8.5 \mathrm{~dB}$, but the measured value showed a difference of 3.7 to $5 \mathrm{~dB}$. The difference might be due to the electrical reflectance between the laser and the signal generator. The theoretical calculation and the experimental result showed the low input impedance laser had higher electrical and optical conversion efficiency. 


\section{O/E converters configured with PIN-PD and various type amplifiers}

There are several different types of InGaAs PIN-PDs, front-ends, and packages for the candidate of the $\mathrm{O} / \mathrm{E}$ converters, since the high speed digital communication and multichannel wideband analog communication have developed the high performance PINPDs, the low impedance front-end, the transimpedance front end, and the reliable packages[8]. Four different types of the O/Es were configured as a cost effective solution of the design of the O/E converter, A linear PIN-PD designed for analog modulation, and a high speed PIN-PD designed for the $2.5 \mathrm{~Gb} / \mathrm{s}$ or $10 \mathrm{~Gb} / \mathrm{s}$ speeds were used. Two different types of packages of the coaxial pigtailed type and the ROSA type were used. Four different types of the pre-amplifiers designed with multi stages GaAs Enhancement-Mode Pseudomorphic High Electron Mobility Transistor (EP-HEMT), or with a combination of GaAs Trans-impedance Amplifier (TIA) and the EP-HEMT amplifier, were configured. The reason of the use of the EP-HEMT was to achieve low voltage single power supply, low noise figure, and high power gain. Table 3.2 shows the O/E converters that were fabricated with various parameters of those components to investigate the optimum performance. The $\mathrm{O} / \mathrm{E}$ conversion gain of those $\mathrm{O} / \mathrm{E}$ converters was measured with the light-wave optical component analyzer (N4373A+N5230A, Agilent). The 2.5Gb/s digital PIN-PD has a $2 \mathrm{k} \Omega$ trans-impedance amplifier in the ROSA package, and is followed by a $15 \mathrm{~dB}$ gain EP-HEMT amplifier. The total gain measured with the optical component analyzer was $33.8 \mathrm{~dB}$. The $10 \mathrm{~Gb} / \mathrm{s}$ digital PIN-PD has a $1.5 \mathrm{k} \Omega$ TIA and a low gain pre-amplifier in the coplanar type package. The total gain measured with the optical component analyzer was $35 \mathrm{~dB}$. The preamplifier used in the $10 \mathrm{~Gb} / \mathrm{s} \mathrm{O} / \mathrm{E}$ converter has a gain control function.

\begin{tabular}{|c|c|c|c|c|}
\hline Symbol & PIN1-AMP1 & PIN2-AMP2 & PIN3-AMP3 & PIN1-AMP4 \\
\hline \multirow{2}{*}{$\begin{array}{c}\text { Block } \\
\text { Diagram }\end{array}$} & $1 x$ & $2 x$ & 3.3. & D \\
\hline & $+\boldsymbol{Y}=\mathrm{AMP}$ & AMP & & \\
\hline \multicolumn{5}{|l|}{ Photograph } \\
\hline Configuration & $\begin{array}{c}\text { PIN-Pigtail } \\
(2 \mathrm{GHz}- \\
\text { Analog })+ \\
\text { AMP(17dB) }\end{array}$ & $\begin{array}{c}\text { ROSA (PIN- } \\
\text { TIA) }(2.4 \mathrm{GHz}- \\
\text { Digital, } \\
\mathrm{Zt}=2 \mathrm{k} \Omega)+ \\
\mathrm{AMP}(15 \mathrm{~dB})\end{array}$ & $\begin{array}{c}\text { PIN-TIA } \\
\text { (10Gb/s- } \\
\text { Digital, } \\
\mathrm{Zt}=1.5 \mathrm{k} \Omega)+ \\
\mathrm{AMP}(15 \mathrm{~dB})\end{array}$ & $\begin{array}{c}\text { PIN-Pigtail } \\
(2 \mathrm{GHz}- \\
\text { Analog)+ } \\
\text { AMP(17dB)+ } \\
\text { AMP(29dB) }\end{array}$ \\
\hline $\begin{array}{c}\mathrm{O} / \mathrm{E} \\
\text { Conversion } \\
(2.5 \mathrm{GHz})\end{array}$ & $19 \mathrm{~dB}$ & $33.8 \mathrm{~dB}$ & $35 \mathrm{~dB}$ & $44.8 \mathrm{~dB}$ \\
\hline
\end{tabular}

Table 3.2. O/E converters with PIN-PD and EP-HEMT Amplifiers 
The O/E conversion of the laser is able to be derived by the following equation;

$$
\eta_{O E}=20 \cdot \log \left(\frac{1}{50} \cdot S_{R} \cdot Z_{t} \cdot 10^{\frac{G_{v}}{20}}\right)[d B]
$$

where, $\eta_{O E}$ is Optical and Electrical conversion efficiency $[\mathrm{dB}], \quad 50$ is the measurement equipment input impedance [ $\Omega], \quad S_{R}$ is responsivity of the PIN-PD, $Z_{t}$ is the transimpedance $[\Omega], G_{v}$ is the pre-amplifier gain $[\mathrm{dB}]$.

\subsection{RCE measurements at $\mathbf{3 0}$ to $40 \mathrm{~km}$ WiMAX RoF transmission}

In the experiments of the evaluation of the $\mathrm{E} / \mathrm{O}$ and $\mathrm{O} / \mathrm{E}$ converters, a downlink WiMAX signal (IEEE 802.16) with $10 \mathrm{MHz}$ BW and with multi burst sub-frames of BPSK, QPSK, 16QAM, and 64QAM, was used at a $2.4 \mathrm{GHz}$ carrier frequency. The received signal error was evaluated by using the RCE that indicated average-error for all the sub-frames modulations. The WiMAX signal was generated by a VSG ( E4438C, Agilent), and was converted to optical signal by the E/O converters. After the transmission over a SMF, the optical signal was converted to electrical signal by the $\mathrm{O} / \mathrm{E}$ converter. The received signal was analysed by a VSA ( 89600 , Agilent).

The WiMAX downlink standard of the IEEE802.16 requires a value of $-30 \mathrm{~dB}$ for the RCE as the maximum value at the access point. The RCE measured for the FP-LD, the DFB-LD, the low and $50 \Omega$ input impedances are shown in Fig.3.4. The SMF length was $30 \mathrm{~km}$. The DFBLD showed the lowest RCE. This is due to the lower relative intensity noise (RIN, about $155 \mathrm{~dB} / \mathrm{Hz}$ ) of the DFB-LD. The low input-impedance DFB-LD showed lower RCE, this was due to the high electrical and optical conversion efficiency (see Table.3.1).

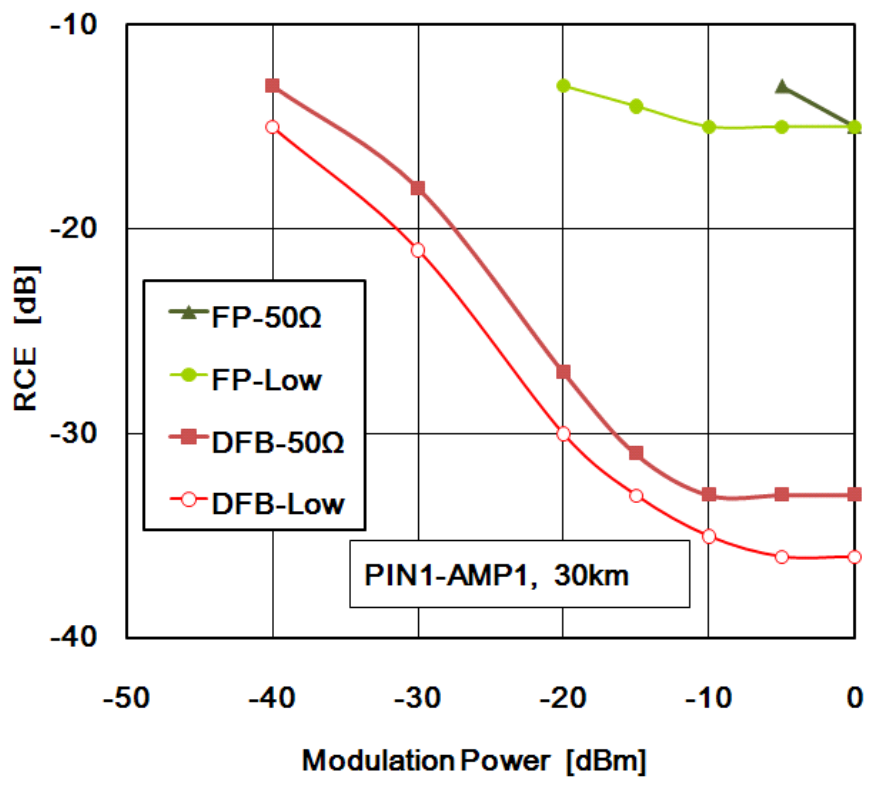

Fig. 3.4. RCE measured with FP-LD, DFB-LD, low input-impedance, and $50 \Omega$ inputimpedance. 
Figure3.5 shows the RCE measured for the three different types of the O/Es. The PIN1AMP1 was configured with a linear PIN-PD and an EP-HEMT amplifier (17dB gain at $2 \mathrm{GHz}$ ). The intrinsic layer of the linear PIN-PD was optimized for the low distortion modulation. The PIN2-AMP2 was a ROSA that was configured with a PIN-PD and a $2 \mathrm{k} \Omega$ GaAs TIA designed for $2.5 \mathrm{~Gb} / \mathrm{s}$ digital transmission. The PIN1-AMP4 was configured with a linear PIN-PD and a high gain EP-HEMT amplifier (44.8dB gain at $2 \mathrm{GHz}$ ). Each amplifier gain was confirmed on the measurements with the light-wave optical component analyzer (N4373A+N5230A, Agilent) and with the received electrical power measured at the VSA. The linear type analog PIN-PD of the type of PIN1 showed lower RCE than that of the digital PIN-PD of the type of PIN2 that was followed by relatively high gain TIA, as shown in Fig.3.5. The low gain PIN1-AMP1 showed lower RCE than that of the PIN2-AMP2. This is due to the low distortion conversion in the analog PIN-PD.

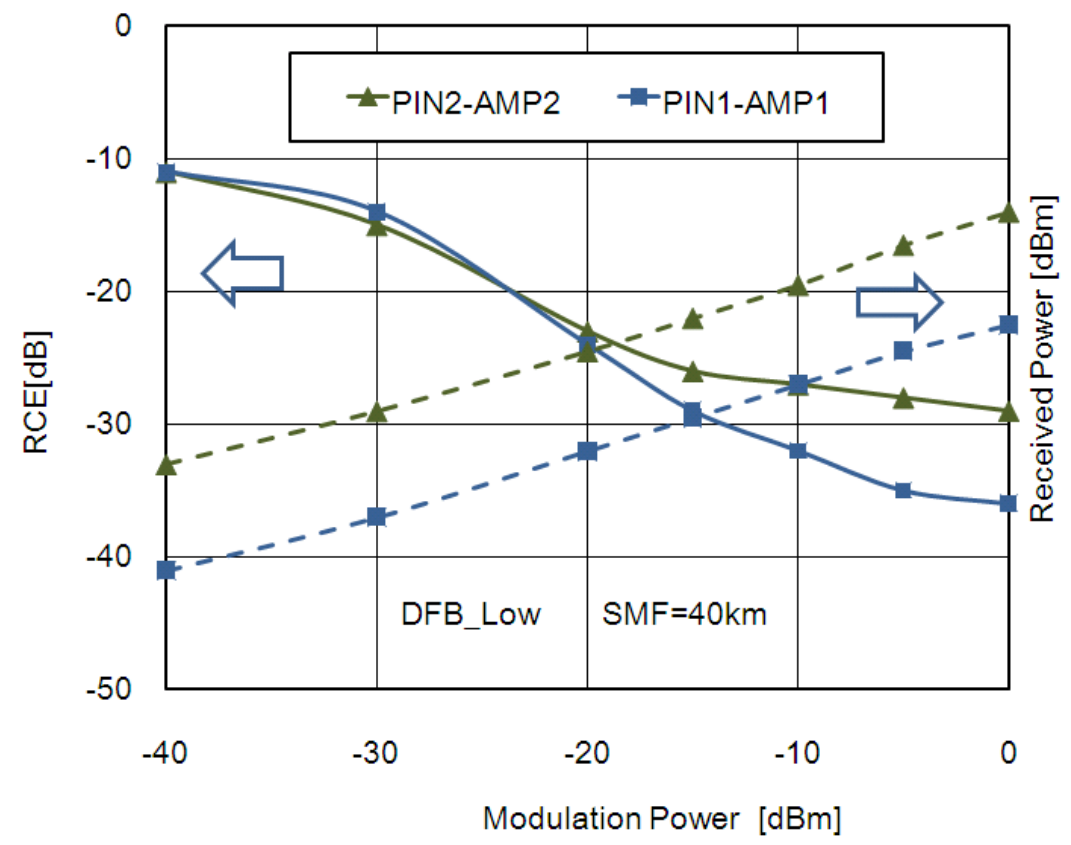

Fig. 3.5. RCE measured with analog PIN-PD (PIN1-AMP1) and 2.5Gb/s digital PIN-PD (PIN2-AMP2).

In the WiMAX RoF link, the use of the linear PIN-PD is strictly important to reduce the RCE. In general, the linear PIN-PD is achieved by a specific design of the structure [9]. The diameter of the window layer has to be determined by the received power, the focused size of the input light beam, and the capacitance. When increasing the diameter, the linearity in the higher optical power level is improved, but the cut-off frequency becomes lower. The length of the intrinsic layer determines the higher optical power level. The longer length is suitable, if the electric field is high, the distribution of the impurities is uniform, and the carrier density is low. The maximum length of the intrinsic layer is around the inverse of the optical absorption coefficient. The longer length of the intrinsic layer may cause the long 
carrier drift time, a low electric field, and lack of the uniformity. Since the PIN-PD designed for the high speed digital application has a small diameter and a short intrinsic layer, the optical linearity is not sufficient for the WiMAX communication.

\begin{tabular}{|c|c|c|c|}
\hline O/E & $\begin{array}{c}\text { RCE } \\
{[\mathrm{dB}]}\end{array}$ & $\begin{array}{c}\text { Rec.Pwr } \\
{[\mathrm{dBm}]}\end{array}$ & $\begin{array}{c}\text { O/E Conv. } \\
{[\mathrm{dB}]}\end{array}$ \\
\hline PIN1-AMP1 & -32 & -28 & 19 \\
\hline PIN2-AMP2 & -27 & -39 & 33.8 \\
\hline Difference & 5 & 11 & 14.8 \\
\hline
\end{tabular}

Table. 3.3. RCE measured with analog PIN-PD (PIN1-AMP1) and 2.5Gb/s digital PIN-PD (PIN2-AMP2).

\section{Conclusions}

It is possible to minimize the influence of the PMD and the PML by optimizing the carrier frequency, the fiber length, the type of the fiber, and the type of the coupler. The burst signal received power of the RoF of WiMAX was determined by the transmitter modulation, when the RoF link was configured with optically and electrically linear characteristic components. Therefore it is strictly important to use the linear PIN-PD for the optical receiver. Since the RCE in the RoF of the WiMAX was related to the burst signal receiver power, the RCE was expressed in the linear relation with the burst signal received power. The experimental data and theoretical data mostly coincided within $2 \mathrm{~dB}$ for the received power and the RCE.

An optimum design of the $\mathrm{E} / \mathrm{O}$ and the $\mathrm{O} / \mathrm{E}$ converters for a cost effective access point was carried out. Four different types of the E/O converters and four different types of the O/E converters were evaluated with the RCE on a WiMAX RoF link using a $2.5 \mathrm{GHz}$ carrier signal. At the transmission link between 30 and $40 \mathrm{~km}$, to satisfy the lower cost and the RCE less than $-30 \mathrm{~dB}$, it is suitable to use the $1310 \mathrm{~nm}$ DFB-LD with a pigtailed package, the lower input impedance than $10 \Omega$, and an EP-HEMT multistage amplifier with the gain larger than $40 \mathrm{~dB}$. In this case, it is also strictly important to use the linear PIN-PD that was originally designed for analog transmission.

\section{References}

[1] Prasanna A. Gamage, et.al.(2008). Power Optimized Optical Links for Hybride Access Networks. Opto-Electronics and Communications Conference (OECC) and the Australian Conference on Optical Fibre Technology (ACOFT), Australia, July 7-10, 2008

[2] Koyu Chinen (2008). RCE Measurements in ROF of IEEE802.16 - 2004 (WiMAX) with Structurally Optimized DFB Lasers. The 8 th International Conference on Wireless and Optical Communications (WOC2008), Canada, May 26-28, 2008, pp.48-52 
[3] H.Al-Raweshidy and S. Komaki (2002). Radio over Fiber Technologies for Mobile Communications Networks (Artech House, 2002) Chap.4 .

[4] Andrey Kobyakov. et.al.(2006). 802.11a/g WLAN Radio Transmission at 1.3 um over 1.1 $\mathrm{km}$ Multi-mode and $>30 \mathrm{~km}$ Standard Single-mode Fiber Using InP VCSEL. In Proc. ECOC 2006, Cannes, France, 2006, Paper Tu1.6.1.

[5] Mohammad Shaifur Rahman, Jung Hyun Lee, Youngil Park, and Ki-Doo Kim (2009). Radio over Fiber as a Cost Effective Technology for Transmission of WiMAX Signals. World Academy of Science, Engineering and Technology, vol. 56, pp.424-428, (2009)

[6] Chien-Hung Yeh, Chi-WaiChow, Yen-Liang Liu, Sz-Kai Wen, Shi-Yang Chen, ChorngRen Sheu, Min-Chien Tseng, Jiunn-Liang Lin, Dar-Zu Hsu, and Sien Chi (2010). Theory and Technology for Standard WiMAX Over Fiber in High Speed Train Systems. Journal of Lightwave Technology, vol.28, No.16, Aug. 15, pp.2327-2336, (2010)

[7] Charles H.Cox, III (2004). Analog Optical Links, Cambridge University Press

[8] Eduard Sackinger(2005). Broadband Circuits for Optical Fiber Communications, John Wiley \& Sons, Inc.

[9] Avigdor Brillant (2008). Digital and Analog Fiber Optic Communications for CATV and FTTx Applications, SPIE and John Wiley \&Sons, Inc. 


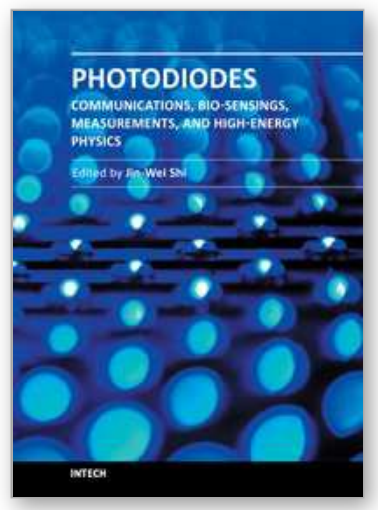

\author{
Photodiodes - Communications, Bio-Sensings, Measurements and \\ High-Energy Physics
}

Edited by Associate Professor Jin-Wei Shi

ISBN 978-953-307-277-7

Hard cover, 284 pages

Publisher InTech

Published online 06, September, 2011

Published in print edition September, 2011

This book describes different kinds of photodiodes for applications in high-speed data communication, biomedical sensing, high-speed measurement, UV-light detection, and high energy physics. The photodiodes discussed are composed of several different semiconductor materials, such as $\mathrm{InP}, \mathrm{SiC}$, and $\mathrm{Si}$, which cover an extremely wide optical wavelength regime ranging from infrared light to X-ray, making the suitable for diversified applications. Several interesting and unique topics were discussed including: the operation of highspeed photodiodes at low-temperature for super-conducting electronics, photodiodes for bio-medical imaging, single photon detection, photodiodes for the applications in nuclear physics, and for UV-light detection.

\title{
How to reference
}

In order to correctly reference this scholarly work, feel free to copy and paste the following:

Koyu Chinen (2011). The Optimum Link Design Using a Linear PIN-PD for WiMAX RoF Communication, Photodiodes - Communications, Bio-Sensings, Measurements and High-Energy Physics, Associate Professor Jin-Wei Shi (Ed.), ISBN: 978-953-307-277-7, InTech, Available from:

http://www.intechopen.com/books/photodiodes-communications-bio-sensings-measurements-and-highenergy-physics/the-optimum-link-design-using-a-linear-pin-pd-for-wimax-rof-communication

\section{INTECH}

open science | open minds

\section{InTech Europe}

University Campus STeP Ri

Slavka Krautzeka 83/A

51000 Rijeka, Croatia

Phone: +385 (51) 770447

Fax: +385 (51) 686166

www.intechopen.com

\section{InTech China}

Unit 405, Office Block, Hotel Equatorial Shanghai

No.65, Yan An Road (West), Shanghai, 200040, China

中国上海市延安西路65号上海国际贵都大饭店办公楼405单元

Phone: +86-21-62489820

Fax: +86-21-62489821 
(C) 2011 The Author(s). Licensee IntechOpen. This chapter is distributed under the terms of the Creative Commons Attribution-NonCommercialShareAlike-3.0 License, which permits use, distribution and reproduction for non-commercial purposes, provided the original is properly cited and derivative works building on this content are distributed under the same license. 